\title{
Changes in Thoracic Kyphosis and Thoracolumbar Kyphosis in Asymptomatic Korean Male Subjects Aged > 50 Years: Do They Progress Above T5, T10, T12, or L2?
}

\author{
Jae-Hong Park ${ }^{1}$, Youngbae B. Kim², Seung-Jae Hyun ${ }^{3}$, Kyu-Bok Kang ${ }^{2}$, Pil-Sun Park ${ }^{2}$ \\ ${ }^{1}$ Department of Orthopedics, Asan Medical Center, Seoul, Korea \\ ${ }^{2}$ Department of Orthopedics, Seoul Veterans Hospital, Seoul, Korea \\ ${ }^{3}$ Department of Neurosugery, Seoul National University Bundang Hospital, Seoungnam, Korea
}

\begin{abstract}
Study Design: Retrospective analysis of prospectively collected data.
Purpose: To evaluate the natural progression of segmental kyphosis in thoracic and thoracolumbar spine with advancing age.

Overview of Literature: To our knowledge, the evolution of segmental thoracic kyphosis (TK) in individuals aged >50 years has not been reported.

Methods: Total 179 normal, asymptomatic Korean men were divided in to three groups (6th, 7th, and 8th decade) according to their age. Standard sagittal spinopelvic parameters, including TK and thoracolumbar kyphosis, were measured and subdivided into the following four segments: A (C7 upper end plate [UEP]-T5 UEP), B (T5 UEP-T10 UEP), C (T10 UEP-T12 lower end plate [LEP]), and D (T12 LEP-L2 LEP). These segments of the three study groups were analyzed.

Results: In segment B, the segmental kyphosis of group $3\left(20.2^{\circ} \pm 8.0^{\circ}\right)$ showed a statistically larger value than that of group 1 $\left(15.6^{\circ} \pm 6.8^{\circ}\right)$ and group $2\left(16.7^{\circ} \pm 8.8^{\circ}\right)(p=0.017)$. In segment $C$, the segmental kyphosis of group $2\left(12.9^{\circ} \pm 6.5^{\circ}\right)$ and group $3\left(12.2^{\circ} \pm 7.1^{\circ}\right)$ showed statistically larger values than that of group $1\left(9.5^{\circ} \pm 6.2^{\circ}\right)(p=0.016)$. The $A$ and $D$ segments of the three groups were not significantly different.

Conclusions: Increased TK was observed in the middle (segment B) and lower (segment C) thoracic segments in normal asymptomatic male subjects with age. The results from the natural progression of segmental kyphosis with age would provide baseline reference data to help surgeons choose the optimal point of the upper instrumented vertebra level for preventing proximal junctional kyphosis.
\end{abstract}

Keywords: Thoracic spine; Thoracolumbar spine; Old age; Asymptomatic; Proximal junctional kyphosis; Progression

\section{Introduction}

Thoracic kyphosis (TK) increases with age and is known to influence the changes in sagittal alignment of other parts in the spine [1]. Kang et al. [2] reported that TK continues to progress in normal subjects after the age of

Received Feb 24, 2019; Revised May 7, 2019; Accepted May 9, 2019

Corresponding author: Youngbae B. Kim

Department of Orthopedics, Seoul Veterans Hospital, 53, Jinhwangdo-ro 61-gil, Gangdong-gu, Seoul 05368, Korea

Tel: +82-2-2225-1352, Fax: +82-2-2225-1910, E-mail: drortho@korea.com 
50 years. A comparison study of segmental TK between young and old adults demonstrated that middle and lower TK were increased; however, the proximal TK was decreased in older subjects [3]. To our knowledge, the evolution of segmental kyphosis in those aged $>50$ years has not been reported.

Proximal junctional kyphosis (PJK) develops after the surgery for adult spinal deformity, often causing clinical symptoms and needing revision surgery [4-10]. The selection of the level of the upper instrumented vertebra (UIV) is an important factor for avoiding the development of PJK in the surgery for adult spinal deformity [11-15]. However, to our knowledge, the differences in the radiographic change patterns as per UIV levels have not been documented.

The present study was conducted to demonstrate the changes in the detailed segmental sagittal thoracic spinal parameters in old normal asymptomatic men (age $>50$ years) and evaluate the natural progression of kyphosis in the thoracic and thoracolumbar spine with age. We aimed to obtain baseline reference data to help surgeons choose the optimal point of the UIV level for preventing PJK.

\section{Materials and Methods}

\section{Demographic data}

The data were gathered from normal asymptomatic Korean volunteers in Veterans Healthcare System Medical Center from March 2007 to June 2011 after gaining the Institutional Review Board approval (IRB no., 2018-10004). The study was done with informed consent to all included patients. Subjects without a history of chronic back pain or leg pain were included. Those with a history of trauma, disease, or operation or intervention (injection or acupuncture) for their back or lower extremities were excluded. Patients who had undergone surgery in the thoracoabdominal area were also excluded from this study.

Total 179 subjects with an average age of $65.2 \pm 6.8$ years (range, 53-83 years) were enrolled. They were divided into three groups as per their age decade. Groups 1, 2, and 3 composed of subjects in the 6th, 7th, and 8th decade, respectively. The average height, weight, and body mass index (BMI) of each group were measured and compared.

\section{Radiographic data}

Radiographs were obtained with the method of Horton et al. [16]. The subjects were asked to stand in a position with the hip and knee joint extended, with both hands over the clavicle, maintaining frontal gaze (Fig. 1). They were stored into PACS (Picture Archiving Communications System, Maroview; Marotch, Seoul, Korea) in the format of DICOM (Digital Imaging and Communications in Medicine). Then, we excluded the subjects showing $>10^{\circ}$ scoliosis or spina bifida in the coronal view, spondylolisthesis, one to three-segment intervertebral disc space narrowing, or compression fracture in the sagittal radiograph.

Various sagittal distance and angular parameters were measured using the Surgimap software (Spine software; Nemaris Inc., New York, NY USA) for radiologic measurements. Global sagittal balance was measured as the horizontal distance $(\mathrm{cm})$ between the plumbline of the center of the seventh cervical vertebra (C7 plumb) and the vertical line from the posterior corner of the sacral
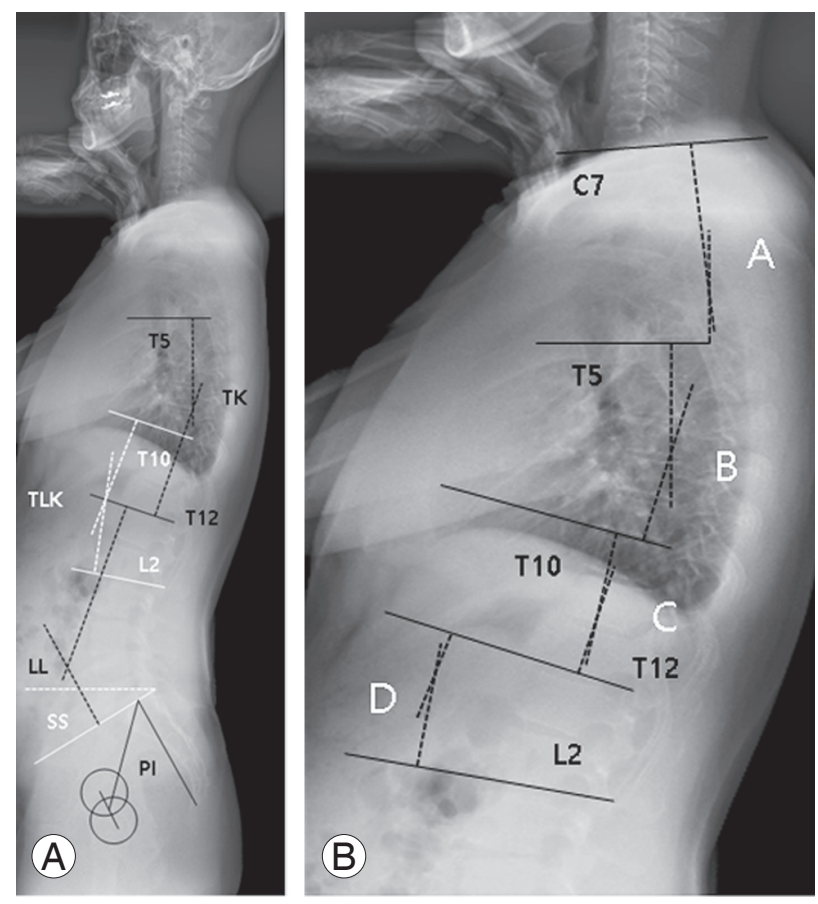

Fig. 1. (A) The angular parameters representing TK (T5 UEP-T12 LEP), TLK (T10 UEP-L2 LEP), and total LL (T12 LEP-S1 UEP). SS and PI are measured as pelvic parameters. (B) TK and TLK were divided into four segments: segment A: C7 UEP-T5 UEP; segment B: T5 UEP-T10 UEP; segment C: T10 UEP-T12 LEP; and segment D: T12 LEP-L2 LEP. TK, thoracic kyphosis; TLK, thoracolumbar kyphosis; LL, lumbar lordosis; SS, sacral slope; PI, pelvic incidence; UEP, upper end plate; LEP, lower end plate. 
end plate. A positive value meant forward transition, and a negative value meant backward transition with reference to the posterior corner of the sacral end plate. Sagittal angular parameters were measured as below: TK (T5 upper end plate [UEP]-T12 lower end plate [LEP]), thoracolumbar kyphosis (TLK, T10 UEP-L2 LEP), and lumbar lordosis (LL, T12 LEP-S1 UEP). TK and TLK were subdivided into the following four segments: A (C7 UEP-T5 UEP), B (T5 UEP-T10 UEP), C (T10 UEP-T12 LEP), and D (T12 LEP-L2 LEP). The sacral slope (SS) and pelvic incidence (PI) were measured as pelvic parameters. The SS was defined as the angle between the line composing the superior plate of S1 and a horizontal line. The PI was defined as the angle between a line from the midpoint of both, the femoral head center to the halved point of the superior plate of $S 1$ and a line rectangular to this point.

\section{Statistical data}

The descriptive statistics were reported in the form of mean, range, and standard deviation values. Analysis of variance was used to assess the differences in the continuous variables of the three groups, followed by Turkey's post-hoc test. A $p$-value $<0.05$ was considered statistically significant. The bivariate correlation between the variables was examined using the Pearson correlation coefficient. Statistically significant correlation coefficients were considered clinically large if $>0.6$, moderate if $>0.4$, and small if $>0.2$. The data were analyzed using IBM SPSS ver. 22.0 (IBM Corp., Armonk, NY, USA).

\section{Results}

\section{Demographic data}

Groups 1, 2, and 3 comprised 48, 85, and 46 patients, respectively. The average height, weight, and BMI of the three groups did not show any statistically significant difference (Table 1).

Table 1. Demographic data

\begin{tabular}{|c|c|c|c|c|c|}
\hline \multirow{2}{*}{ Characteristic } & \multirow{2}{*}{ Total } & \multicolumn{3}{|c|}{ Age group } & \multirow{2}{*}{$p$-value } \\
\hline & & 1 & 2 & 3 & \\
\hline Age (yr) & $65.2 \pm 6.8$ & 6th & 7th & 8th & \\
\hline No. of patients & 179 & 48 & 85 & 46 & \\
\hline Height (cm) & $166.8 \pm 5.4$ & $167.9 \pm 5.1$ & $166.3 \pm 5.5$ & $166.6 \pm 5.7$ & 0.29 \\
\hline Weight $(\mathrm{kg})$ & $67.0 \pm 9.5$ & $67.6 \pm 11.0$ & $67.0 \pm 9.4$ & $66.2 \pm 7.5$ & 0.83 \\
\hline Body mass index $\left(\mathrm{kg} / \mathrm{m}^{2}\right)$ & $24.1 \pm 3.1$ & $23.9 \pm 3.4$ & $24.2 \pm 3.2$ & $23.9 \pm 2.3$ & 0.80 \\
\hline
\end{tabular}

Values are presented as mean \pm standard deviation or number (\%). Group 1: 6th decade (range, 51-60 years); group 2: 7th decade (range, 61-70 years); and group 3: 8th decade (range, 71-80 years).

a,b) Indicate statistically significant differences.

Table 2. Global sagittal parameters

\begin{tabular}{|c|c|c|c|c|c|}
\hline \multirow{2}{*}{ Variable } & \multirow{2}{*}{ Total } & \multicolumn{3}{|c|}{ Age group } & \multirow{2}{*}{$p$-value } \\
\hline & & 1 & 2 & 3 & \\
\hline C7 plumb (cm) & $-0.4 \pm 2.5$ & $-0.6 \pm 2.2$ & $-0.1 \pm 2.4$ & $-0.5 \pm 3.0$ & 0.199 \\
\hline Thoracic kyphosis $\left({ }^{\circ}\right)$ & $29.6 \pm 9.1$ & $27.0 \pm 7.7^{\text {a) }}$ & $30.3 \pm 10.0^{b)}$ & $32.2 \pm 8.3^{b)}$ & 0.018 \\
\hline Thoracolumbar kyphosis $\left({ }^{\circ}\right)$ & $10.0 \pm 7.4$ & $7.9 \pm 6.6^{\text {a) }}$ & $11.0 \pm 7.4^{b)}$ & $11.2 \pm 8.1^{b)}$ & 0.041 \\
\hline Lumbar lordosis $\left({ }^{\circ}\right)$ & $56.7 \pm 8.6$ & $55.0 \pm 8.4$ & $57.8 \pm 8.0$ & $56.5 \pm 9.8$ & 0.187 \\
\hline Sacral slope $\left(^{\circ}\right)$ & $36.9 \pm 6.8$ & $35.7 \pm 6.4$ & $37.1 \pm 6.4$ & $37.7 \pm 7.6$ & 0.352 \\
\hline Pelvic incidence $\left({ }^{\circ}\right)$ & $48.1 \pm 9.2$ & $47.6 \pm 7.8$ & $48.3 \pm 8.2$ & $49.4 \pm 9.3$ & 0.595 \\
\hline
\end{tabular}

Values are presented as mean \pm standard deviation, unless otherwise stated. Group 1: 6th decade (range, 51-60 years); group 2: 7th decade (range, 61-70 years); and group 3: 8th decade (range, 71-80 years).

a,b) Indicate statistically significant differences. 


\section{Global sagittal parameters}

There were no statistically significant differences among the three groups with respect to the average degrees of LL, SS, PI, and the distance of C7 plumb (Table 2). The average TK angle in the study population was $29.6^{\circ} \pm 9.1^{\circ}$. The mean TK angles of the three groups were as follows: $27.0^{\circ} \pm 7.7^{\circ}$ in group $1,30.3^{\circ} \pm 10.0^{\circ}$ in group 2 , and $32.2^{\circ} \pm 8.3^{\circ}$ in group 3. Groups 2 and 3 showed statistically larger values than group $1(p=0.018)$. The average TLK angle was $10.0^{\circ} \pm 7.4^{\circ}$ in the study population, $7.9^{\circ} \pm 6.6^{\circ}$ in group $1,11.0^{\circ} \pm 7.4^{\circ}$ in group 2 , and $11.2^{\circ} \pm 8.1^{\circ}$ in group 3. Groups 2 and 3 showed statistically larger values than group $1(p=0.041)$.

\section{Thoracic segmental sagittal parameters}

Among the four segments, segment A, or the cephalad segment and segment $\mathrm{D}$, or the caudal segment of TK and

Table 3. Thoracic segmental sagittal parameters $\left({ }^{\circ}\right)$

\begin{tabular}{|c|c|c|c|c|c|}
\hline \multirow{2}{*}{ Segment } & \multirow{2}{*}{ Total } & \multicolumn{3}{|c|}{ Age group } & \multirow{2}{*}{$p$-value } \\
\hline & & 1 & 2 & 3 & \\
\hline A & $9.3 \pm 6.9$ & $9.3 \pm 6.7$ & $10.0 \pm 6.5$ & $7.8 \pm 7.5$ & 0.218 \\
\hline B & $17.3 \pm 8.3$ & $15.6 \pm 6.8^{\text {a) }}$ & $16.7 \pm 8.8^{\text {a) }}$ & $20.2 \pm 8.0^{\mathrm{b})}$ & 0.017 \\
\hline C & $11.5 \pm 6.7$ & $9.5 \pm 6.2^{a)}$ & $12.9 \pm 6.5^{b /}$ & $12.2 \pm 7.1^{b)}$ & 0.016 \\
\hline D & $-1.9 \pm 6.1$ & $-2.2 \pm 6.5$ & $-2.2 \pm 6.1$ & $-0.9 \pm 5.8$ & 0.449 \\
\hline
\end{tabular}

Values are presented as mean \pm standard deviation, unless otherwise stated. Group 1: 6th decade (range, 51-60 years); group 2: 7th decade (range, 61-70 years); and group 3: 8th decade (range, 71-80 years).

$a, b)$ Indicate statistically significant differences.

Table 4. Pearson correlations coefficients among sagittal parameters

\begin{tabular}{llllll} 
& TK & TLK & LL & SS & PI \\
\hline TK & 1 & & & & \\
TLK & $0.239^{* *}$ & 1 & & & \\
\hline LL & $0.375^{*}$ & 0.021 & 1 & & \\
SS & 0.034 & 0.106 & $0.761^{* *}$ & 1 & 1 \\
\hline PI & 0.146 & 0.070 & $0.585^{* *}$ & $0.667^{* *}$ & 1 \\
\hline
\end{tabular}

TK, thoracic kyphosis; TLK, thoracolumbar kyphosis; LL, lumbar lordosis; SS, sacral slope; Pl, pelvic incidence.

${ }^{*} p<0.05 .{ }^{* *} p<0.01$.
TLK did not show any statistically significant difference among the three evaluated age groups (Table 3). In group $\mathrm{B}$, the segmental kyphosis angle was $15.6^{\circ} \pm 6.8^{\circ}$ in group $1,16.7^{\circ} \pm 8.8^{\circ}$ in group 2 , and $20.2^{\circ} \pm 8.0^{\circ}$ in group 3. Group 3 showed a significantly larger value than groups 1 and 2 $(p=0.017)$. In group $\mathrm{C}$, the segmental kyphosis angle was $9.5^{\circ} \pm 6.2^{\circ}$ in group $1,12.9^{\circ} \pm 6.5^{\circ}$ in group 2 , and $12.2^{\circ} \pm 7.1^{\circ}$ in group 3. Groups 2 and 3 showed statistically larger values than group $1(p=0.016)$.

\section{Correlations}

Strong correlations were observed between LL and SS $(r=0.761, p<0.01)$ as well as between SS and PI $(r=0.667$, $p<0.01)$. Moderate correlations were observed between LL and PI $(r=0.585, p<0.001)$. There was a weak correlation between TK and LL $(r=0.375, p<0.001)$ (Table 4, Fig. 2$)$.

\section{Discussion}

The present study aimed to evaluate the natural progression of segmental kyphosis in the thoracic and thoracolumbar spine with age in old, normal asymptomatic men. $\mathrm{PJK}$ includes a wide range of symptoms, ranging from a symptomless deformity to severe pain that may require revision surgery $[9,10,17]$. However, it is fundamentally a radiographic pathologic that develops in the transitional region, usually between the UIV and two levels above the UIV. Of the numerous risk factors, including surgical, radiographic, and patient-specific risk factors, the choice of UIV plays a crucial role in the development of PJK [10]. Spinal movements and dynamics are grossly changed after fixation at the proximal junction because the dynamic component is lost after segment fixation. We have attempted to provide baseline reference data that would

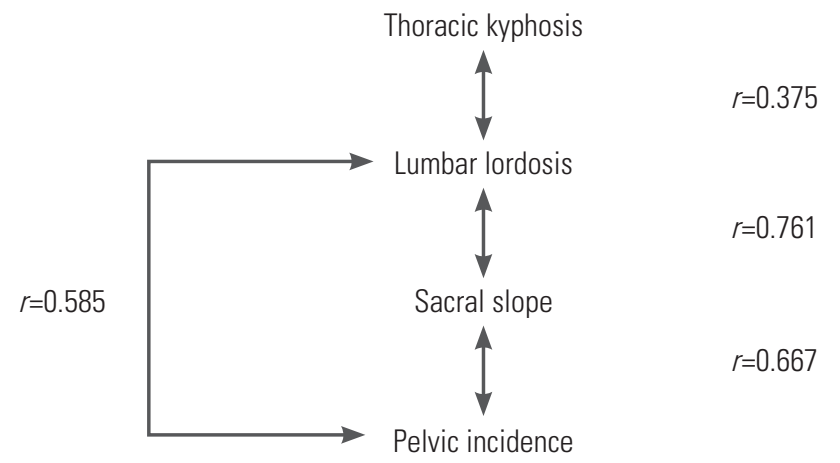

Fig. 2. Chain of correlations. 
help surgeons choose the optimal point of the UIV level and predict the progression of PJK.

The global progression of kyphosis in the thoracic spine according to age has been evaluated by several authors $[2,18]$. In our study, TK and TLK were divided into four segments according to the influence of different anatomy and important fixation points of the UIV in spine surgery. Segment A (C7 UEP-T5 UEP) was made for evaluating the altering complex cervicothoracic area with age and comparing the junctional changes after upper thoracic fusion. Segment B (T5 UEP-T10 UEP) was assigned for observing the changes in the thoracic area protected from the support of the rib cages and comparing the junctional changes after lower thoracic fusion. Segments C (T10 UEP-T12 LEP) and D (T12 LEP-L2 LEP) were used for identifying the transformation of the thoracolumbar junction with age and comparing the result after upper lumbar fusion.

The kyphosis angle increased with age in segments $B$ and $\mathrm{C}$. However, the magnitudes of the average changes over 2 decades were $<5^{\circ}$. We demonstrated no natural kyphogenic tendencies in the upper thoracic and lower thoracolumbar area, and the magnitude of progression was lower than PJK after the surgery. The definition of $\mathrm{PJK}$ is $>10^{\circ}$ or $20^{\circ}$ of two vertebrae above the fusion level after 1 or 2 years of the surgery $[17,19,20]$. In this study, the authors showed only the tendency or the direction of kyphosis progression. The incidence of PJK of the UIV in the upper thoracic region is reportedly less than that in the lower thoracic area $[17,21]$. Our result showed a lordogenic tendency above the upper thoracic UIV and kyphogenic tendency above the lower thoracic UIV. In this study, the magnitude of natural progression was smaller than that of pathologic PJK, and the cutoff value was not suggested. However, by considering the direction of progression in each segment, the surgeons could expect future sagittal parameters in segmental levels and analyze the partial influence of the natural phenomenon on kyphosis progression after surgery.

In segments $A$ and $D$, we found no statistically significant changes. Some surgeons advocate extending the fusion to the upper thoracic region for patients likely to develop PJK following initial scoliosis correction, in spite of the disadvantages of a longer operative time, greater estimated blood loss, and higher postoperative complications [20-22]. Our data demonstrated that there is no kyphogenic tendency above T5. Some surgeons argue that the thoracolumbar junction (T10-L2 or segments C and D) has unique anatomic characteristics that predispose an individual to PJK $[11,23]$. It serves as the transitional zone between the thoracic and lumbar spine, with respect to the different mobility, changing facet orientation, and reciprocal sagittal curvature. The present result showed that the lower part of the thoracolumbar junction did not show progression in kyphosis with age.

There are certain limitations of the present study. First, we only collected the data of male subjects because of the nature of the subject population at the author's institute. Second, the data are from a cross-sectional study. Third, this study was based on radiologic data of Koreans. Comparative studies are needed to apply the change in the segmental thoracic curve to other races [24-26]. Finally, we enrolled a relatively small sample size; therefore, the four segments could not be subdivided. Moreover, further research on the principles of changes in the spinal dynamics after segmental fixation should be undertaken.

\section{Conclusions}

Increased TK was observed in the middle (segment B) and lower (segment $\mathrm{C}$ ) thoracic segments in normal asymptomatic male subjects with age. In the upper thoracic (segments A) and lower thoracolumbar (segment D) segments, there was no statistically significant change.

\section{Conflict of Interest}

No potential conflict of interest relevant to this article was reported.

\section{References}

1. Kim YB, Kim YJ, Ahn YJ, et al. A comparative analysis of sagittal spinopelvic alignment between young and old men without localized disc degeneration. Eur Spine J 2014;23:1400-6.

2. Kang KB, Kim YJ, Muzaffar N, Yang JH, Kim YB, Yeo ED. Changes of sagittal spinopelvic parameters in normal Koreans with age over 50. Asian Spine J 2010;4:96-101.

3. Kang GB, Ahn YJ, Kim YJ, Kim YB, Ko YR. A comparative analysis of thoracic and thoracolumbar kyphosis between young men and old men. J Korean Orthop Assoc 2016;51:48-53. 
4. Cho SK, Shin JI, Kim YJ. Proximal junctional kyphosis following adult spinal deformity surgery. Eur Spine J 2014;23:2726-36.

5. Lau D, Clark AJ, Scheer JK, et al. Proximal junctional kyphosis and failure after spinal deformity surgery: a systematic review of the literature as a background to classification development. Spine (Phila Pa 1976) 2014;39:2093-102.

6. Reames DL, Kasliwal MK, Smith JS, Hamilton DK, Arlet V, Shaffrey CI. Time to development, clinical and radiographic characteristics, and management of proximal junctional kyphosis following adult thoracolumbar instrumented fusion for spinal deformity. J Spinal Disord Tech 2015;28:E106-14.

7. Nguyen NL, Kong CY, Hart RA. Proximal junctional kyphosis and failure: diagnosis, prevention, and treatment. Curr Rev Musculoskelet Med 2016;9:299308.

8. Yan C, Li Y, Yu Z. Prevalence and consequences of the proximal junctional kyphosis after spinal deformity surgery: a meta-analysis. Medicine (Baltimore) 2016;95:e3471.

9. Hyun SJ, Lee BH, Park JH, Kim KJ, Jahng TA, Kim HJ. Proximal junctional kyphosis and proximal junctional failure following adult spinal deformity surgery. Korean J Spine 2017;14:126-32.

10. Kim HJ, Iyer S. Proximal junctional kyphosis. J Am Acad Orthop Surg 2016;24:318-26.

11. Shufflebarger H, Suk SI, Mardjetko S. Debate: determining the upper instrumented vertebra in the management of adult degenerative scoliosis: stopping at T10 versus L1. Spine (Phila Pa 1976) 2006;31(19 Suppl):S185-94.

12. Kim YJ, Bridwell KH, Lenke LG, Rhim S, Kim YW. Is the T9, T11, or L1 the more reliable proximal level after adult lumbar or lumbosacral instrumented fusion to L5 or S1? Spine (Phila Pa 1976) 2007;32:265361.

13. Cho KJ, Suk SI, Park SR, Kim JH, Jung JH. Selection of proximal fusion level for adult degenerative lumbar scoliosis. Eur Spine J 2013;22:394-401.

14. Lafage R, Line BG, Gupta S, et al. Orientation of the upper-most instrumented segment influences proximal junctional disease following adult spinal deformity surgery. Spine (Phila Pa 1976) 2017;42:1570-7.

15. Yasuda T, Hasegawa T, Yamato Y, et al. Proximal junctional kyphosis in adult spinal deformity with long spinal fusion from T9/T10 to the ilium. J Spine Surg 2017;3:204-11.

16. Horton WC, Brown CW, Bridwell KH, Glassman SD, Suk SI, Cha CW. Is there an optimal patient stance for obtaining a lateral 36 " radiograph?: a critical comparison of three techniques. Spine (Phila Pa 1976) 2005;30:427-33.

17. Bridwell KH, Lenke LG, Cho SK, et al. Proximal junctional kyphosis in primary adult deformity surgery: evaluation of 20 degrees as a critical angle. Neurosurgery 2013;72:899-906.

18. Fon GT, Pitt MJ, Thies AC Jr. Thoracic kyphosis: range in normal subjects. AJR Am J Roentgenol 1980;134:979-83.

19. Glattes RC, Bridwell KH, Lenke LG, Kim YJ, Rinella A, Edwards C 2nd. Proximal junctional kyphosis in adult spinal deformity following long instrumented posterior spinal fusion: incidence, outcomes, and risk factor analysis. Spine (Phila Pa 1976) 2005;30:1643-9.

20. Maruo K, Ha Y, Inoue $S$, et al. Predictive factors for proximal junctional kyphosis in long fusions to the sacrum in adult spinal deformity. Spine (Phila Pa 1976) 2013;38:E1469-76.

21. Hostin R, McCarthy I, O'Brien M, et al. Incidence, mode, and location of acute proximal junctional failures after surgical treatment of adult spinal deformity. Spine (Phila Pa 1976) 2013;38:1008-15.

22. Annis P, Lawrence BD, Spiker WR, et al. Predictive factors for acute proximal junctional failure after adult deformity surgery with upper instrumented vertebrae in the thoracolumbar spine. Evid Based Spine Care J 2014;5:160-2.

23. Cho KJ, Kim YT, Shin SH, Suk SI. Surgical treatment of adult degenerative scoliosis. Asian Spine J 2014;8:371-81.

24. Yokoyama K, Kawanishi M, Yamada M, et al. Agerelated variations in global spinal alignment and sagittal balance in asymptomatic Japanese adults. Neurol Res 2017;39:414-8.

25. Zhu Z, Xu L, Zhu F, et al. Sagittal alignment of spine and pelvis in asymptomatic adults: norms in Chinese populations. Spine (Phila Pa 1976) 2014;39:E1-6.

26. Mac-Thiong JM, Roussouly P, Berthonnaud E, Guigui P. Sagittal parameters of global spinal balance: normative values from a prospective cohort of seven hundred nine Caucasian asymptomatic adults. Spine (Phila Pa 1976) 2010;35:E1193-8. 